\title{
How to Improve the Dynamic Conditions of the Troops, According to the Army Grass-Roots Construction Program to Grasp the Level of Construction
}

\author{
Bo Liu ${ }^{1, a *}$, Wei Wang ${ }^{2, b}$ \\ 1,2No.1 huayuan road, economic development zone, Changchun, Jilin province, China \\ a 935491752@qq.com,b453041770@qq.com
}

Keywords: To improve; Dynamic conditions; Qrasp construction level

\begin{abstract}
In recent years, all the military and military personnel of the real soldier, the exercise drills the task into normalization. Under the dynamic conditions of the army, it has become a regular pattern in accordance with the basic construction of military infrastructure. How to carries out normalized diverse tasks, hold the characteristic of dynamic forces under the condition of construction development ,always adhere to the military base construction program to grasp ,high standard construction units, the successful completion of the task, is important subject in front of us.

Under the dynamic conditions, the army should grasp the level of construction at the grass-roots level of the army. First of all, we must grasp the dynamic conditions of the troops, the construction of several distinct characteristics ${ }^{[1]}$. The so-called dynamic, on the one hand, the central task of the troops will not change, and then the work of the troops will be carried out around the center. Training, education, management, security, and other key elements should be adjusted. The construction of the army is always in a state of discontinuity and lack of continuity. On the other hand, with the transformation of the central task, the troops have been performing tasks for a long time, the surrounding environment is constantly changing, and the army's level mode of construction is changing accordingly. Personnel, equipment, vehicles, including the thought of officers and soldiers, organization and construction are always in the dynamic, which gives the troops a great impact on the level, sustainability and sustainability of construction.
\end{abstract}

\section{In Order to Firmly Establish the Dynamic Conditions, We Should Follow the Outline of the Military Infrastructure and Grasp the Consciousness of Construction}

In recent years, under the dynamic conditions, the army has made great progress, and it has also revealed that it is not fast enough to grasp the basic ideas of the grassroots, under dynamic conditions, the construction of the characteristics of the construction of the troops are uncertain, and the problems of the conflict between tasks and construction are not well solved ${ }^{[2]}$. All this has had a profound impact on the development of science. So we must first of all, to further improve the ideological understanding, attaches great importance to the construction of troops into, follow the objective law of construction development and grasp forces constantly stresses the basic groundwork, strengthened according to the army at the grassroots level construction outline to grasp the construction of consciousness, through the solid foundation construction to guarantee the successful completion of each task.

Fully Recognizing the Dynamic Conditions, It is the Fundamental Guarantee to Complete the Task According to the Outline of the Military Infrastructure and the Construction ${ }^{[3]}$. The army is combat effectiveness, performance in wartime, accumulation is platform, formed in the battlefield, derived from the base, with foreign countries, the development of the domestic situation changing and expanding functions of military mission, army carries out temporary sudden major task difficulty has become the norm. This needs us to recognize the situation, change ideas, fully understand in quite a long time in the future, under dynamic condition, the construction has become the norm mode, only not to relax, fully understand on a military base construction outline to grasp, to pay special attention to the regular solid groundwork, implement, to continuously 
generate the fighting capacity, enhance battle effectiveness.

Fully Aware of the Dynamic Conditions, According to the Basic Construction of the Army is An Effective Way to Promote Scientific Development ${ }^{[4]}$. Promoting the construction of the armed forces and comprehensively coordinating the sustainable development is an inherent requirement to the thoroughly implement the scientific outlook on development, and also an eternal task and long-term task of strengthening the army's construction. From the point of the future, more and more task force will only burden will be more and more heavy ,no matter in what environment what period, all is a phase in the development of military construction, temporary concept cannot exist and surprise ideas. In order to fully recognize the dynamic conditions, the army should grasp the constructions of the basic level of the army ${ }^{[5]}$, which is the long-term plan for the development of the army's construction, rather than the expedient of periodic construction, it is necessary to continue to do good work, strong foundation of the project, and not the principle of high-sounding. We should focus on the overall situation, pursue long-term development, and firmly establish a firm ideological and political foundation, the more arduous the task, the better the infrastructure. To break bureaucrats' backs to study and do a good job, the characteristics of the military construction law under the dynamic condition,solid out of ideas,organization,training,management and safeguard all aspects such as the foundation, to force construction of sustainable development to provide a strong motivation and strong support.

\section{In Order to Accurately Grasp the Dynamic Conditions, the Army Should Follow the Outline of the Army's Grass-roots Construction}

Laying the Foundations of Though and Politics. President Xi stressed that listening to the party's command is the soul of a strong army, and that political work is the lifeblood of our army. Especially under the dynamic conditions ${ }^{[6]}$, the troops face higher political test, the officers and soldiers face the reality of more and more fluctuation, and put forward higher requirements for the ideological and political work of the army. Therefore, we should keep chose to the situation, keep close to the task, and keep close to the thoughts of the officers and soldiers, to cultivate the core values of the modern revolutionary soldiers, and to play the leading role of the party, can win the ideological and political foundation of good work style. Adopt the method of combining with the combination of the cutting needle and the combination, and use all kinds of carriers to make the decision of the superior decision, to combat the mission of the situation combat spirit and policies and regulations, and so on, keep the propaganda work throughout, and keep the constant thought work throughout. We will continue to solve ideological problems, combine psychological problems with practical problems, and focus on helping the officers and soldiers to listen to the political beliefs of the party, and set up the correct and optimistic outlook on honor and disgrace, and create a good atmosphere in the happiness. This ensures that the troops are firmly in command, ensuring that the soldiers maintain high morale and morale.

Strengthening the Construction of the Team. Breaking the military cadres of political cadres logistic cadres, cadres equipment line, forces the comprehensive construction, pays special attention to the cadres of the learning training and help to strengthen the training of cadres comprehensive quality, strengthening the role of cadres ${ }^{[7]}$. For task situation bring cadre thought pressure, carry out special education, leading cadres to find problem seriously, improvement, and consciously strengthen the cadre responsibility consciousness, sense of mission, and sense of dedication. In view of the actual situation of the army's dynamics, it is necessary to increase the performance of cadres in a variety of ways, follow-up inspection of the discipline and discipline, and ensure that the cadres are constantly under management. Always implement the people-oriented concept, fully considering the forces under the dynamic, to the cadre of the impact of family, earnestly for the cadres to do the practical work, help the cadres to solve the problem, do a good job in the families of safeguard cadres personal interests. Arouse the enthusiasm of cadre work, solve the worry, enhance the team cohesion. At the same time, efforts to strengthen the construction of the ranks, cultivate good organization and good cadre training, strengthen the psychological research, strengthen the role and play the role in the first step. Strict procedure and standard selection of 
sergeants, retain good professional technical backbone. We will step up management, strictly implement the rules and regulations, eliminate the specialization of the petty officers, and prevent the problems of the petty officials themselves.

Upholding the Rule of Law and Strictly Control the Armed Forces ${ }^{[8]}$. Must adhere to all management activities, as for doctrine regulation specification before, strictly implement the system of life a day, and all standard of the regularized management. To full its full refers to a comprehensive range of strict management, this is the army under the condition of dynamic stresses the safe and stable work of the special discipline, must be taken seriously, must be strictly implemented, ensure the officers and soldiers in the word and deed is under effective control. And to actively explore the characteristics of the dynamic environment security and stability work, establish and improve the analysis predicts that hidden perils in risk assessment management system mechanism, improve the preventive measures and strictly implement the responsibility system for work safety. Highlight the personnel vehicle, bullet and information control, strengthen the military administrative area, prevent impact, prevent explosion, prevent arson, prevent attack managing strength, we will strictly prevent all kind of crises and major security issues. We should work closely on internal and external relations. And we will vigorously improve the capability of leading cadres in dynamic conditions, adhere to management and education, the combination of dredging and blocking, strict and caring, and the combination of words and teaching, respect and maintenance to the legitimate rights and interests of the soldiers, public treatment, involving the soldiers to join the party, the examination of the commission and the award of meritorious service, the selection of petty officials and other sensitive issues. We should thoroughly prevent the aggravation of injustices and create an atmosphere of unity and harmony and purity.

\section{It is Necessary to Elaborate the Order of Construction According to the Basic Construction of the Army Under Dynamic Conditions}

Improve the Institutional Mechanism. In order to establish a security situation analysis system, no matter how the troops move, we should adhere to the outline of the basic building of the army and analyze the situation of the company ${ }^{[9]}$. Security situation, analysis of forces on a regular basis to summarize the dynamic conditions, in accordance with the army at the grassroots level construction outline, experiences and lessons from the construction company, and analysis the problems and the insufficiency, from finding formulate improvement measures. In order to establish a coordinated and coordinated system, the work should be arranged in a unified way, and the objectives, priorities and measures should be determined by the party committee and the head office, and needing to send troops to further unify our thinking. To coordinate the work, the military and political leader assigned tasks to prevent the occurrence of conflicts. To unify the use of force, according to the work needs to unify the organization, rationally arrange the leadership and the organ strength, play the overall effectiveness.

Improved guidance. Under the new situation and new management mode, the force dynamic deployment mechanism must combine the characteristics of the mission, to advance the integrated guidance of operational command. The head of the army and the organ should understand the transformation of the basic functions profoundly, take the initiative to master the overall situation and different characteristics of the troops, break the boundary between departments, and stand in the overall planning and guidance. Make full use of the effective carrier, hold regular meetings, arrange the work, organize the construction situation of the troops regularly, find the weak links in the construction of the troops, and improve the work guidance measures. It is necessary to shift the guidance from the authorities and the troops to grass-roots level, help the grassroots to understand the depth of task and grasp the accuracy of the problem.

Carrying out coordinated development ${ }^{[10]}$. We will accelerate the realization of complementary sharing of resources. Forces under the dynamic condition, learn from each other, increasing difficulty of all kinds of resources are spread out, by the linkage, can effectively integrate the resources, cross sharing, improve the quality of work efficiency. We will properly integrate the talents of all units, dig into the merits of the officers and soldiers, and regularly organize various 
types of backbone to conduct training activities among various units, on the one hand, develop the characteristic talent, on the other hand the active force internal atmosphere. We should pay more attention to the collection and forwarding of experience practices, and encourage all levels to summarize good experience practices, discuss research, and summarize and summarize a large number of good practices and promote them widely.

\section{References}

[1] B.S .Zhang: Army Military Training(Military Science Press, China 2006).Vol.1,p.163.(In Chinese).

[2] F. Jiang: Introduction to Equipment Sergeant Education Training(PLA Press,China 2012).Vol.1,p.91.(In Chinese).

[3] D.S. Zhang: The Troops Management, Vol.2 98(2018) No.4, p.12.(In Chinese).

[4] X. Yan: The Troops Management, Vol.2 99(2018) No.5, p.1.(In Chinese).

[5] X.Y. Li: Armor Journal, Vol.2 29(2018) No.4, p.77.(In Chinese).

[6] J.W. Li: Armor Journal, Vol.2 29(2018) No.4, p.79.(In Chinese).

[7] Y.Q. Jiao: Political Work Journal, (2017) No.4, p.27.(In Chinese).

[8] C.S. Zhang: Political Work Journal, (2016) No.3, p.20.(In Chinese).

[9] L. Zhang: Political Work Journal, (2015) No.4, p.11.(In Chinese).

[10] S.Q. Li: Journal of Nanjing Institute of Politics, (2015) No.4, p.139.(In Chinese). 